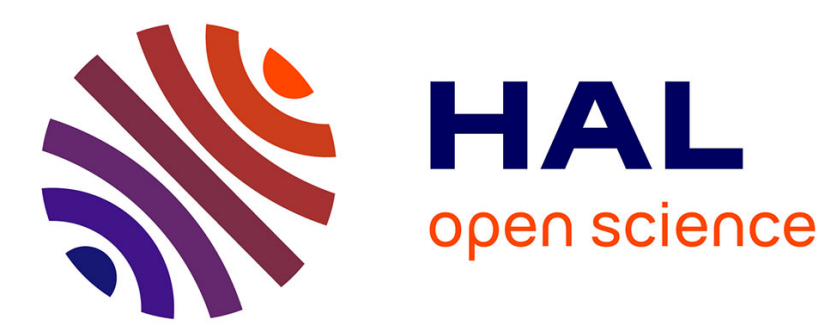

\title{
ELECTRICAL ACTIVITY OF Al DOPED SILICON $\Sigma$ 9 BICRYSTAL BY S.T.E.B.I.C.
}

\author{
T. Benabbas, J.-Y. Laval
}

\section{To cite this version:}

T. Benabbas, J.-Y. Laval. ELECTRICAL ACTIVITY OF Al DOPED SILICON $\sum 9$ BICRYSTAL BY S.T.E.B.I.C.. Journal de Physique IV Proceedings, 1991, 01 (C6), pp.C6-231-C6-236. 10.1051/jp4:1991636 . jpa-00250722

\section{HAL Id: jpa-00250722 https://hal.science/jpa-00250722}

Submitted on 1 Jan 1991

HAL is a multi-disciplinary open access archive for the deposit and dissemination of scientific research documents, whether they are published or not. The documents may come from teaching and research institutions in France or abroad, or from public or private research centers.
L'archive ouverte pluridisciplinaire HAL, est destinée au dépôt et à la diffusion de documents scientifiques de niveau recherche, publiés ou non, émanant des établissements d'enseignement et de recherche français ou étrangers, des laboratoires publics ou privés. 


\title{
ELECTRICAL ACTIVITY OF AI DOPED SILICON $\Sigma 9$ BICRYSTAL BY S.T.E.B.I.C.
}

T. BENABBAS and J.-Y. LAVAL

Laboratoire de Physique du Solide, C.N.R.S - E.S.P.C.I., 10 rue Vauquelin, F-75231 Paris Cedex, France

\begin{abstract}
The influence of aluminium on the electrical properties of silicon bicrystals was analyzed and related to the interaction between impurities and defects. A p-type silicon $\Sigma 9$ symmetrical tilt bicrystal, with a chemical gradient in aluminium was grown by a directional solidification method. The combination of electrical, chemical and structural local information, with high spatial resolution enabled the electrical activity to be correlated to the cristallochemistry of the boundary. It was shown that the recombining activity depends on the localization and environment of aluminium.
\end{abstract}

\section{1-Introduction:}

Grain boundaries and sub-boundaries are the major extended defects in polycristaline silicon. First they diminish the mobility of the majority carriers through their potential barriers. Second, they act as recombining centers for the electron-hole pairs and have a direct effect on the lifetime of minority carriers in the neighbourhood. The potential barrier results from the trapping of majority carriers by deep level states. Such states can hardly be created by dangling bonds present at the boundary since their density is likely to be small, as a result of the lattice reconstruction in the boundary plane $/ 1 /, / 2 /$. However the segregation of impurities at GBs, during the growth, could be conducive to interfacial states which are localized in the forbidden gap /3 - 6/. In polycrystalline silicon, aluminium can act either as an acceptor or as a trap, depending on the thermal treatment and on the location and environment of $\mathrm{Al}$ in the lattice $/ 7 /$.

The investigation of the electrical activity on Al-doped $\Sigma 9 \mathrm{Si}$ bicrystal via the S.T.E.B.I.C technique $/ 8 /$, which is associated to transmission electron microscopy, enables a precise description of the interaction between aluminium and defects in silicon. 


\section{2-Experimental technique:}

Bicrystals were grown at CECM-Vitry by the heat exchange method (H.E.M)/9/ from E.G p-type silicon and melting zone aluminium. The main boundary is kept all along the ingot axis $\left(h_{t}=6 \mathrm{~cm}\right)$. The division coefficient of aluminium in silicon is $210^{-3}$ which leads to a concentration gradient in aluminium from bottom to top of the ingot. Observed samples are extracted from a (221) $\Sigma 9$ symmetrical tilt boundary. Samples for transmission electron microscopy (T.E.M) were ion thinned. T.E.M was performed on a Jeol $100 \mathrm{CX}$ and analytical T.E.M on a Jeol 2000 FX equipped with a Link selective energy analyzer. Defects associated with the boundary are characterized chemically and cristallographically. Then the thinned samples are transformed into thin diodes by depositing a $20 \mathrm{~nm}$ layer of aluminium for the Schottky junction and the ohmic contact is obtained with an AIGa amalgam on the other side of the sample.The diode is mounted on a specific holder provided with electrical connections. The S.T.E.B.I.C current is amplified and modulates the video signal of the S.T.E.M attachment.

\section{3-Results:}

T.E.M reveals that the ingot can be divided into 3 parts. The first one corresponds to an aluminium content $\mathrm{N}_{\mathrm{Al}}<10^{18}$ at $/ \mathrm{cm}^{3}$ and represents $70 \%$ of the full height from the bottom. The $\Sigma 9$ boundary is almost decoration - free. The only precipitates to be observed are parallelepipedic with a mean length of $500 \mathrm{~nm}$, X-ray microanalysis indicates that they are $\mathrm{Ni}$-rich.

S.T.E.B.I.C images show off the lack of electrical activity of the undecorated $\Sigma 9$ GB, (fig 1a,b) and the localization of recombinating processes on the nickel-rich precipitates, (fig $2 a, b)$.

In the second part of the ingot $\left(10^{18}<\mathrm{N}_{\mathrm{Al}}<10^{19} \mathrm{at} / \mathrm{cm}^{3}\right)$, microstresses and/or microprecipitates can be observed.The electrical activity of each of these defects can be visualized on a $\Sigma 9$ and $\Sigma 3$ boundaries, fig $3 a, b$ (the current is reversed, the recombination process leads to white contrast).

Third, the last part, (10\% of the ingot ) correspond to $10^{19}<\mathrm{N}_{\mathrm{Al}}<10^{20} \mathrm{at} / \mathrm{cm}^{3}$. It exhibits a periodic array of precipitates on the $\Sigma 9$ boundary: there mean size is $=25$ $\mathrm{nm}$, (fig $5 \mathrm{a}, \mathrm{c}$ ). A coprecipitation of aluminium and oxygen is evidenced by X-ray microanalysis. A periodic array of dislocations can also be observed, (fig 5c). Such dislocations where $\mathrm{Al}$ only is observed, accomodate the misfit to coincidence. S.T.E.B.I.C (fig 5b) indicates that the decoration at the boundary induces an electrical activity and the specific activity cannot be distinguished any more on each precipitate. On such samples the specific activity of extrinsic dislocations has been displayed $(\Sigma 3$ GB, fig $6 a, b)$. Sub-boundaries are active (fig $7 a, b)$ and the electrical activity of each dislocation can be obtained with a spatial resolution of $100 \mathrm{~nm}$ as indicated on fig $7 \mathrm{c}$. Al segregation is again evidenced on these dislocations. 

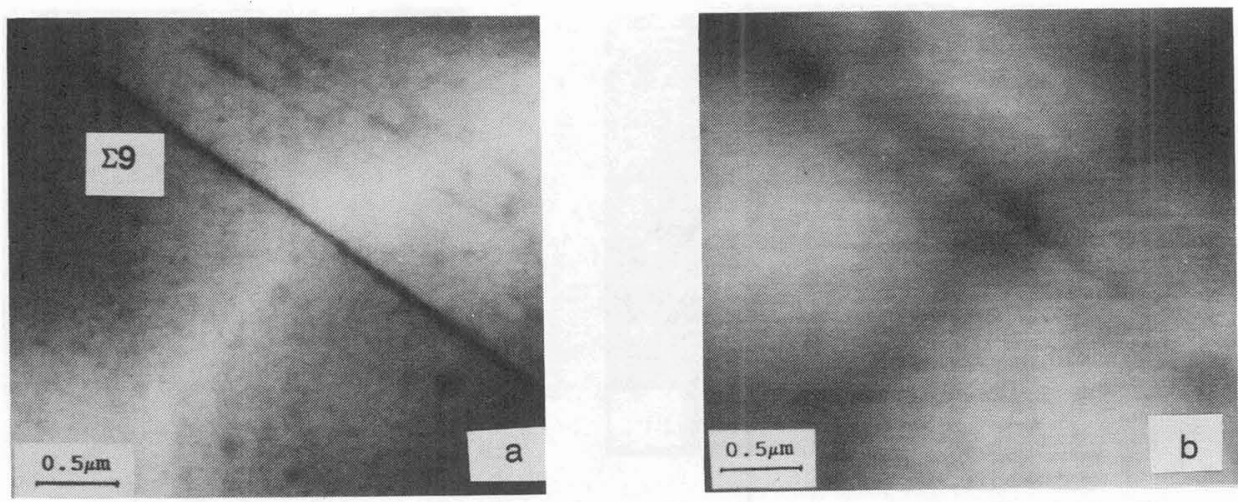

fig 1a,b: Undecorated 29 GB. a - STEM image; b - Corresponding STEBIC image. The STEBIC current is highly sensitive to the diode thickness.
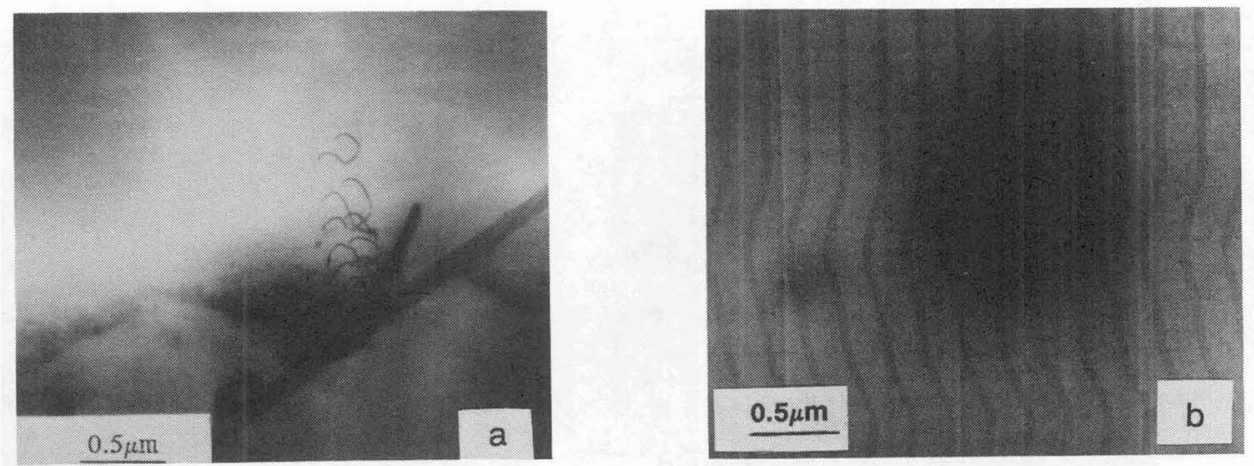

fig 2a,b: $\Sigma 9$ with $\mathrm{Ni}$ - rich precipitates and matrix dislocations. a - TEM image; $b$ - STEBIC image showing the local recombination on precipitate and dislocations . Streaking comes from scanning artifacts.
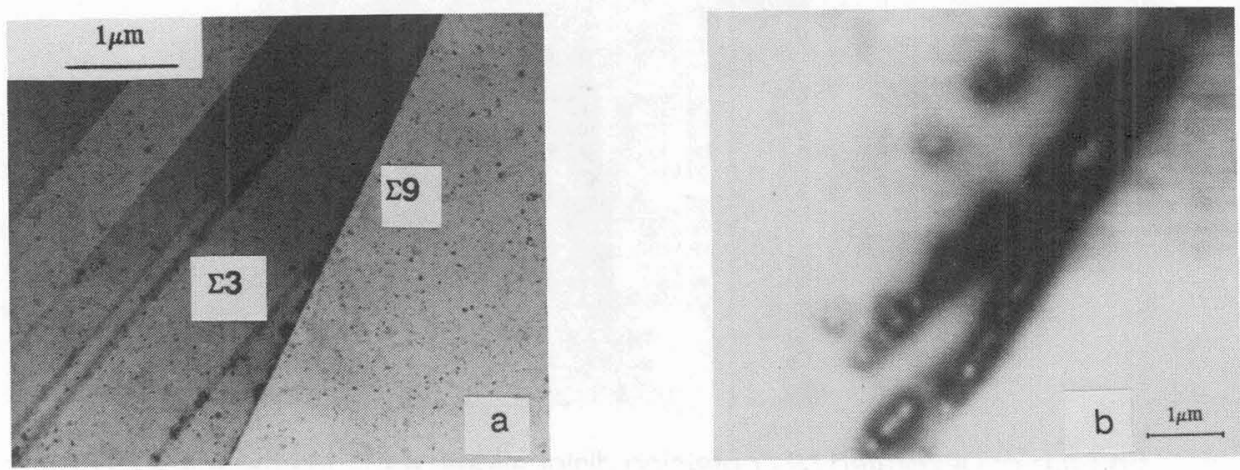

fig 3a,b: Decorated 59 and $\Sigma 3$ boundaries. a - TEM image; $b$ - The electrical activity of each precipitate is visualized on the STEBIC image, reversed contrast. 

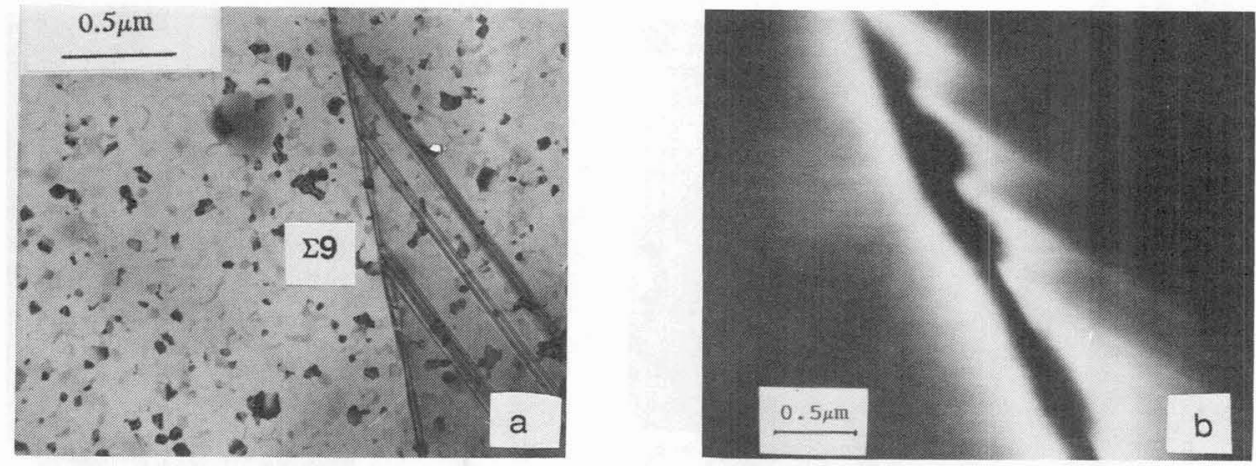

fig 4a,b : Decoration - free $\Sigma 9$ with stacking faults. a - TEM image; b - STEBIC mode: the boundary is recombining, stacking faults are inactive.Small grains scattered on the surface of the sample correspond to Al deposit for the Schottcky junction.
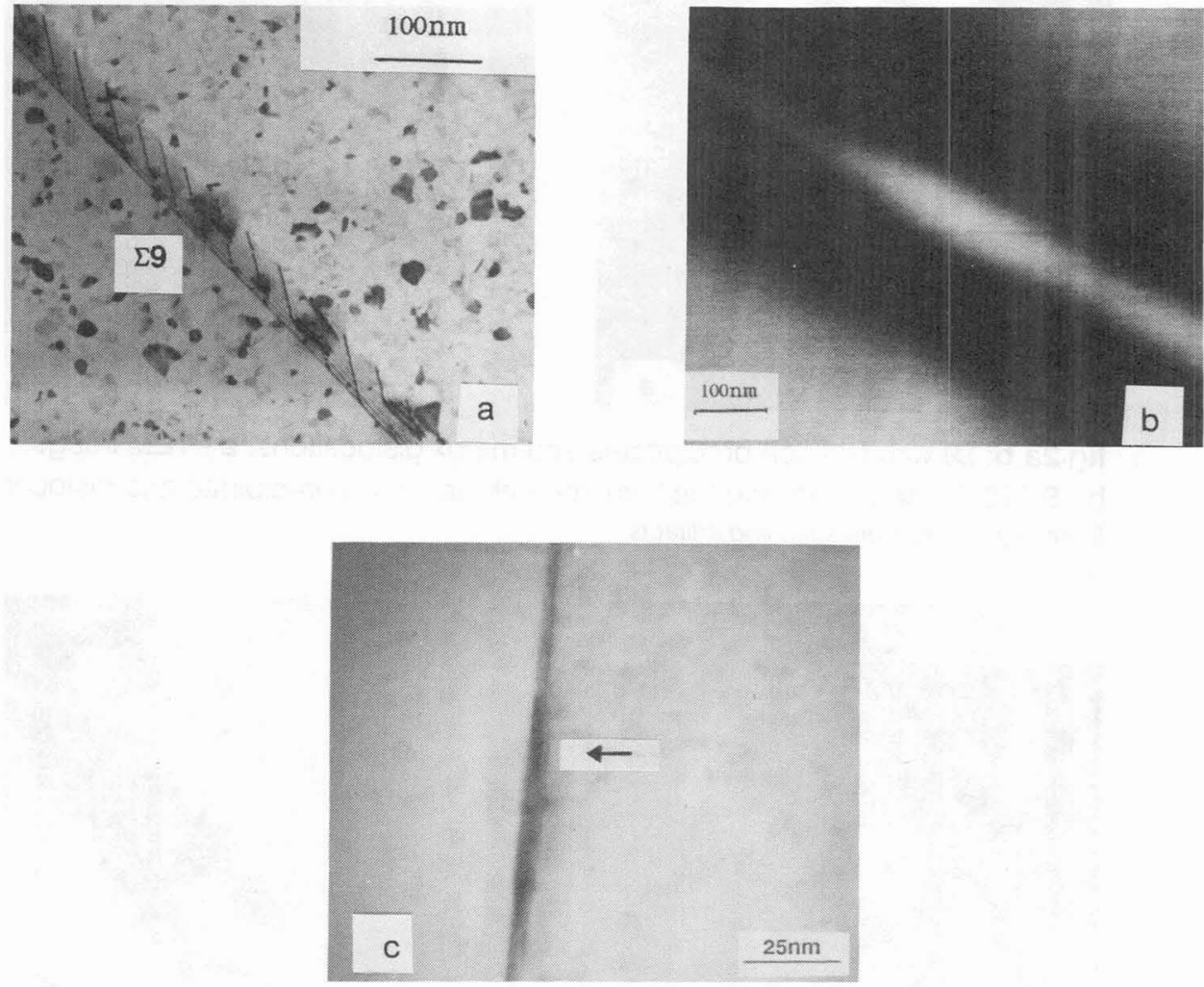

fig 5a,b,c: Decorated $\mathbf{2 9}$ containing dislocations. a - TEM image; b - STEBIC mode: the specific activity of each precipitate (see c) cannot be distinguished; c - stick-like precipitate corresponding to Al and O coprecipitation. 

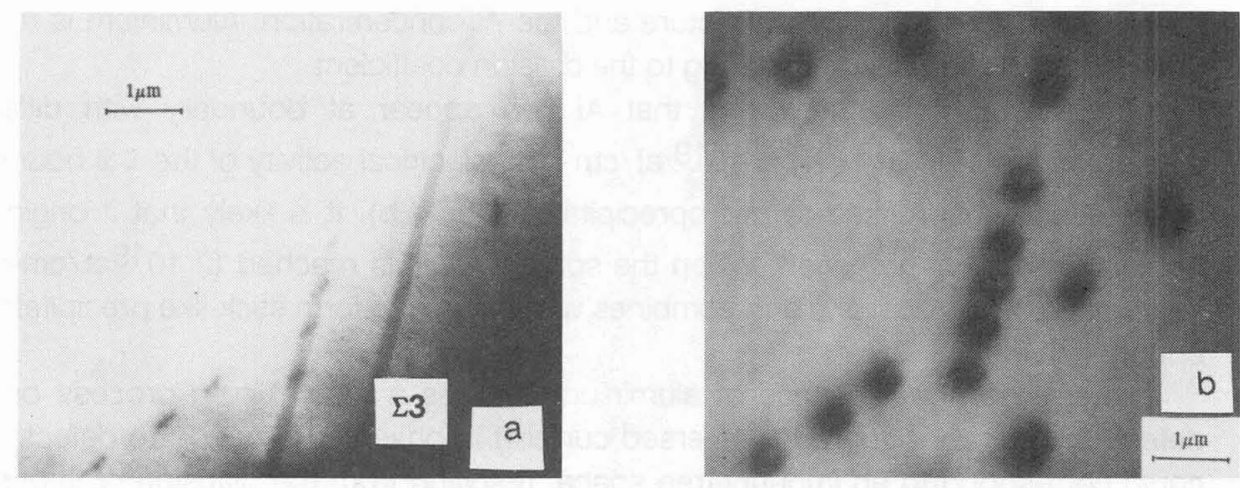

fig 6a,b: a - Extrinsic dislocations on $\Sigma 3$ boundaries (STEM image); b - Specific activity of each dislocation, reversed STEBIC mode.
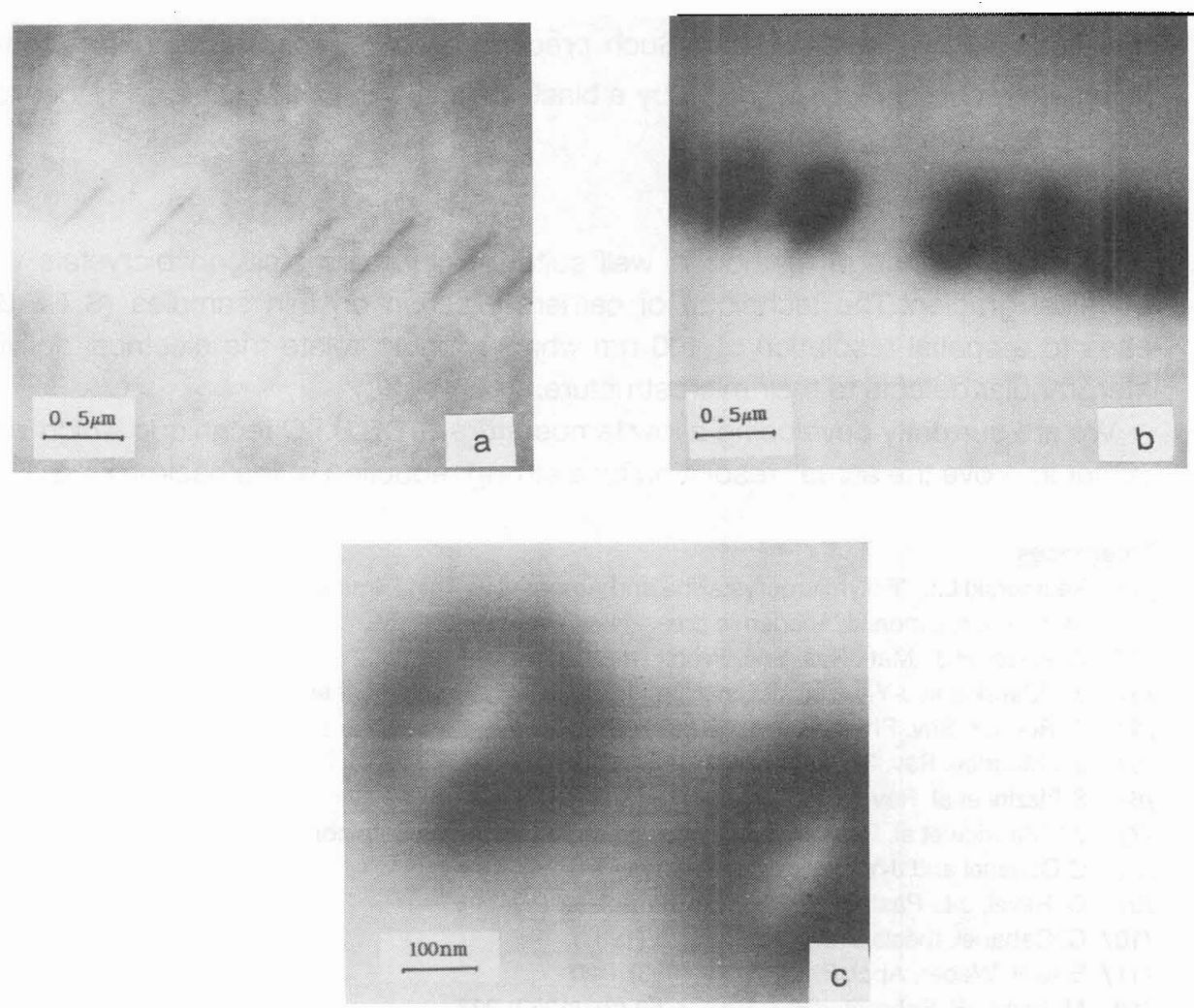

fig 7a,b,c: a - TEM image of a sub-boundary; b - STEBIC image, reversed contrast; $c$ - high magnification STEBIC image on two consecutive dislocations. 


\section{4-Discussion:}

The H.E.M method enables to follow the evolution of the electrical activity of a specific defect with the microstructure and the Al concentration. Aluminium is mainly drawn up by segregation according to the division coefficient.

Furthermore, it is noteworthy that Al can appear at boundary with different configurations. For $10^{18}<\mathrm{N}_{\mathrm{Al}}<10^{19}$ at/ $\mathrm{cm}^{3}$ the electrical activity of the $\Sigma 9$ boundary is not necessarily related to microprecipitates (fig $4 a, b$ ). It is likely that it originates from incipient Al segregation. When the solubility limit is reached $\left(210^{19} \mathrm{at} / \mathrm{cm}^{3}\right), \mathrm{Al}$ segregates on dislocations and combines with oxygen to form stick-like precipitates at boundaries (fig $5 \mathrm{c}$ ).

In any case, the presence of aluminium induces a recombining process on the defect. A clear zone (dark for reversed current) is observed around the defect. This could correspond to an impurity-free space, resulting from the diffusion of impurities towards boundaries or dislocations during the ingot growth, since there is not heat treatment afterwards $/ 10 \%$.

The role of some impurities such as $\mathrm{Ni}$ is also evidenced. $\mathrm{Ni}$ is a fast diffuser in silicon, and the enthalpy of formation for Ni silicides is low /11/. Moreover such platelets have already been observed for $\mathrm{Ni}$-rich precipitates which have been identified as $\mathrm{SiNi}_{2}$ or $\mathrm{SiNi}_{3} / 12 /$. Such precipitates can generate matrix dislocations which are recombining, as shown by a black tail in the S.T.E.B.I.C mode in the vicinity of the precipitate (fig $2 a, b)$.

\section{5-Conclusion :}

The heat exchange method is well suited for preparing silicon bicrystals with a chemical gradient.The technique of carriers injection on thin samples (S.T.E.B.I.C) leads to a spatial resolution of $100 \mathrm{~nm}$ which allow to relate the electrical activity of intergranular defects to their microstructure.

We are currently developing a low temperature S.T.E.B.I.C technique which should further improve the actual resolution by a strong reduction of the background.

\section{References}

/1/ Kazmerski L.L, "Polymicrocrystalline and Amorphous Thin Films and Devices", ed. by L.L Kazmerski, Academic press, New York (1980), p.59

12/ Queisser H.J. ,Mat . Res. Soc. Proc. (1983) 323

13/ J.L Maurice et J-Y. Laval, Journal De Physique, C1, Supplément au n¹0, 43, (1982).

/4/ A. Rocher, Rev. Phys. Appl. 22 (1987) 591.

/5/ J.L.Maurice, Rev. Phys. Appl. 22 (1987) 613.

/6/ S.Pizzini et al. Rev. Phys.Appl. 22 (1987).631.

17/ J.L.Maurice et al. Poly-Micro-Crystalline and Amorphous Semiconducteur (1984).

/8/ C.Cabanel and J-Y. Laval,J. Appl. Phys 67 (1990) 1425.

/9/ G. Revel, J-L. Pastol et al, Rev.Phys. Appl. 22 (1987) 519

/10/ C. Cabanel, thesis University Paris VI (1987).

/11/ Eike R. Weber, Appl. Phys. A 30 (1983) 1-20

/12/ M. Seibt, W. Schroeter;Phil. Mag, A 59 (2), (1989) 237. 